\title{
Brain substrate utilisation during acute hypoglycaemia
}

\author{
J. Wahren ${ }^{1}$, K. Ekberg ${ }^{1}$, E. Fernqvist-Forbes ${ }^{1}$, S. Nair ${ }^{2}$ \\ ${ }^{1}$ Department of Clinical Physiology, Karolinska Hospital, Stockholm, Sweden \\ ${ }^{2}$ Division of Endocrinology, Mayo Clinic, Rochester, Minnesota, USA
}

\section{Abstract}

Aims/hypothesis. Our study was undertaken to examine directly the utilisation of glucose and alternative substrates, in particular amino acids, during hypoglycaemia.

Methods. Catheters were positioned in the jugular venous bulb and an artery in six healthy subjects in the overnight fasted state. Arterio-venous differences for glucose, amino acids, lactate and pyruvate were measured in the basal state, during hyperinsulinaemic euglycaemia and during hyperinsulinaemic hypoglycaemia. The subjects were studied on two different occasions, once during intravenous infusion of amino acids and once during infusion of saline.

Results. In the basal state the fractional extraction of glucose across the brain was $10 \pm 2 \%$, glucose uptake accounted for $106 \pm 5 \%$ of the brain's oxidative metabolism. There was a small release of lactate and pyruvate. During hyperinsulinaemia glucose uptake continued to account for the entire fuel requirement of the brain. Hyperaminoacidaemia did not result in net amino acid uptake by the brain. During hypoglycaemia $(2.4 \pm 0.2 \mathrm{mmol} / \mathrm{l})$ fractional extraction of glucose by the brain increased $(p<0.01)$ and glucose uptake accounted for $90 \pm 15 \%$ of the brain's oxidative metabolism. Uptake of amino acids, lactate or pyruvate could not be detected.

Conclusion/interpretation. 1) Brain fractional extraction of glucose increases during hypoglycaemia, 2) hyperinsulinaemia does not change fractional extraction of glucose by the brain, 3) augmented availability of amino acids does not result in brain amino acid uptake during euglycaemia or hypoglycaemia and 4) under the present study conditions glucose remains the major substrate for cerebral metabolism during hypoglycaemia; lactate or pyruvate uptake by the brain can not be detected. [Diabetologia (1999) 42: 812818]

Keywords Amino acids, normal subjects, jugular vein, lactate, pyruvate, $\beta$-hydroxybutyrate.
It is now clearly established that tight blood glucose control substantially reduces or delays most of the chronic complications in patients with Type I (insulin-dependent) diabetes mellitus [1]. A tight blood glucose control, however, is accompanied by in-

Received: 26 June 1998 and in final revised form: 23 February 1999

Corresponding author: Dr. J. Wahren, Department of Clinical Physiology, Karolinska Hospital, SE-171 76 Stockholm, Sweden

Abbreviations: A-JV, Arterio-jugular venous difference; A-V, arterio-venous difference; RQ, respiratory quotient. creased hypoglycaemic episodes [1]. These recurrent hypoglycaemic episodes are major impediments in achieving ideal blood glucose control in a substantial number of Type I diabetic patients. In studies where alternative fuels, such as $\beta$-hydroxybutyrate and lactate [2] were provided in attempts to alleviate hypoglycaemic symptoms, the response of the autonomic system to hypoglycaemia was diminished or prevented [3]. Based on this indirect evidence, it was concluded that the brain uses these alternative fuels during hypoglycaemia. The brain contains the enzyme systems that are required for the metabolism of a range of different carbohydrate and lipid substrates [4]. There is thus, no immediate reason why the brain 
could not use glycerol, lactate, pyruvate or amino acids.

It has generally been agreed upon that the brain uses glucose almost exclusively as a fuel for its energy need in the overnight fasted state, other substrates making no or minimal contributions [5]. Rather than being taken up, small amounts of lactate and pyruvate are released from the brain in the overnight fasted state in healthy subjects and dogs $[6,7]$. Cerebral uptake of glycerol has not been shown [6]. In contrast, during prolonged fasting (4-5 weeks), when the availability of $\beta$-hydroxybutyrate and acetoacetate increases approximately 50 -fold to 100 -fold, glucose utilisation by the brain decreases [8] and ketone acids become important fuels for the brain, together accounting for $40-50 \%$ of its oxidative metabolism [9]. It is still, however, to be shown whether a similar use of alternative fuels by the brain occurs during hypoglycaemia. Many amino acid concentrations decrease during insulin-induced hypoglycaemia [10], and there is considerable data to suggest that amino acids may act as an alternative fuel to many body tissues $[11,12]$. We therefore hypothesise that replacement of amino acids during hypoglycaemia may provide an alternative fuel to the brain.

Our study was undertaken to examine directly the utilisation of glucose and alternative substrates by the brain under conditions of hypoglycaemia or hyperinsulinaemia or both in healthy subjects. In addition, the possible contribution by amino acids to cerebral substrate utilisation during hypoglycaemia was examined in the basal state and during increased amino acid availability. The study was prompted by the finding that there is a small net uptake of both essential and non-essential amino acids by the brain after an overnight fast $[13,14]$.

\section{Materials and methods}

Subjects. We studied six healthy men, mean age 26 (range 24-28) years, with an average body mass index of $22.2 \mathrm{~kg} / \mathrm{m}^{2}$ (range 19.8 to 24.1). Approval of the study protocol was obtained from the institutional ethics committee at the Karolinska Hospital, Stockholm. The nature, purpose and possible risks of the study were carefully explained to each subject before informed consent was obtained.

Procedure. The subjects were studied on two separate occasions with a 1-2 month interval. The same protocol was used in both studies but amino acids were infused on one occasion and saline on the other. The infusions were given in a random order and the subjects were not aware of the order. The subjects came to the laboratory in the morning of the study day after an overnight fast. With the subjects in the supine position, a catheter (Cournand 7F, USCI, C. R. Bard, Ireland) was inserted percutaneously under local anaesthesia into the right femoral vein and placed under fluoroscopic control in the right jugular vein. The tip of the catheter was positioned just below the base of the skull. Catheters were also inserted into a bra-

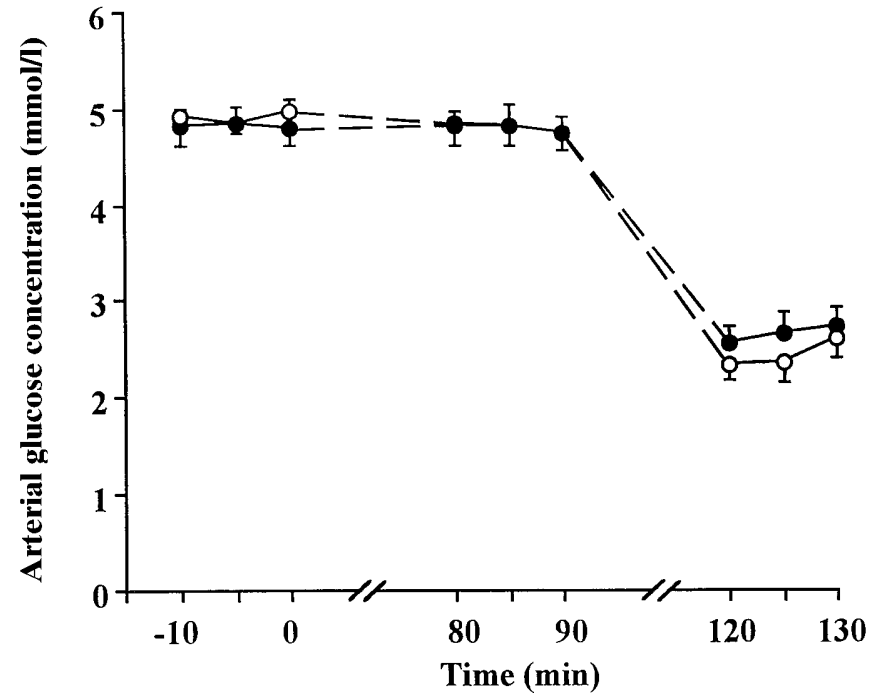

Fig. 1. Arterial glucose concentration in the basal state, during hyperinsulinaemic euglycaemia and during hyperinsulinaemic hypoglycaemia. $\bigcirc$, indicates data obtained during saline infusion, data for amino acid infusion are denoted by, 0 . Means \pm SEM are presented

chial artery and a forearm vein. After 30 min of rest, baseline samples were obtained from the artery and jugular vein in triplicate with 5 min intervals for measurements of glucose, lactate, pyruvate, $\beta$-hydroxybutyrate and amino acid concentrations and oxygen and carbon dioxide contents. Arterial samples were also collected in duplicate for determination of catecholamines, insulin, glucagon and cortisol concentrations in the basal state. Subsequently, a euglycaemic hyperinsulinaemic clamp was started $\left(1.0-1.5 \mathrm{mU} \cdot \mathrm{kg}^{-1} \cdot \mathrm{min}^{-1}\right.$ insulin plus a variable infusion of $20 \%$ glucose), together with an infusion of either $0.9 \%$ saline $(1 \mathrm{ml} / \mathrm{min})$ or an amino acid solution (Vamin, $18 \mathrm{~g} \mathrm{~N} / \mathrm{l}$, Pharmacia, Sweden) at a rate of $1 \mathrm{ml} \cdot \mathrm{kg}^{-1} \cdot \mathrm{h}^{-1}$. The amino acid or saline infusions were continued until the end of the studies. The arterial plasma glucose concentrations were measured every 5 min and the glucose infusion rate was adjusted to maintain the basal blood glucose concentration $( \pm 0.3 \mathrm{mmol} / \mathrm{l})$. At $80-90 \mathrm{~min}$ a new set of blood samples were obtained from the jugular vein and artery, as in the basal state. At 90 min the glucose infusion was gradually reduced to lower the blood glucose concentration to 2.5-3.0 mmol/l (Fig. 1), while determining plasma glucose every $2.5 \mathrm{~min}$. At 130-140 min, when clinical symptoms of hypoglycaemia (perspiration, anxiety, tachycardia, light-headedness etc.) were present in all subjects, a final set of arterial and jugular vein samples were collected. The insulin infusion was then discontinued, the catheters were withdrawn, and the subjects were given a light meal to restore normoglycaemia.

Analyses. Plasma glucose concentrations were measured using a glucose analyser (Beckman Instr., Fullerton, Calif., USA) based on the glucose oxidase reaction. Glucose (the CV was $1.5 \%$ ), lactate (CV 2\%), pyruvate and $\beta$-hydroxybutyrate were determined enzymatically in whole blood, after deproteinisation with perchloric acid as described previously $[15,16]$. Plasma concentrations of amino acids were measured using a HPLC system (Hewlett Packard 1090 series 2 HPLC, 1046 fluorescence detector and cooling system, Hewlett Packard, Palo Alto, Calif., USA) with precolumn $O$-phthalaldehyde derivatization [17]. The CVs for determination of individual amino ac- 
Table 1. Arterial concentrations of substrates and hormones and $\mathrm{pCO}_{2}$

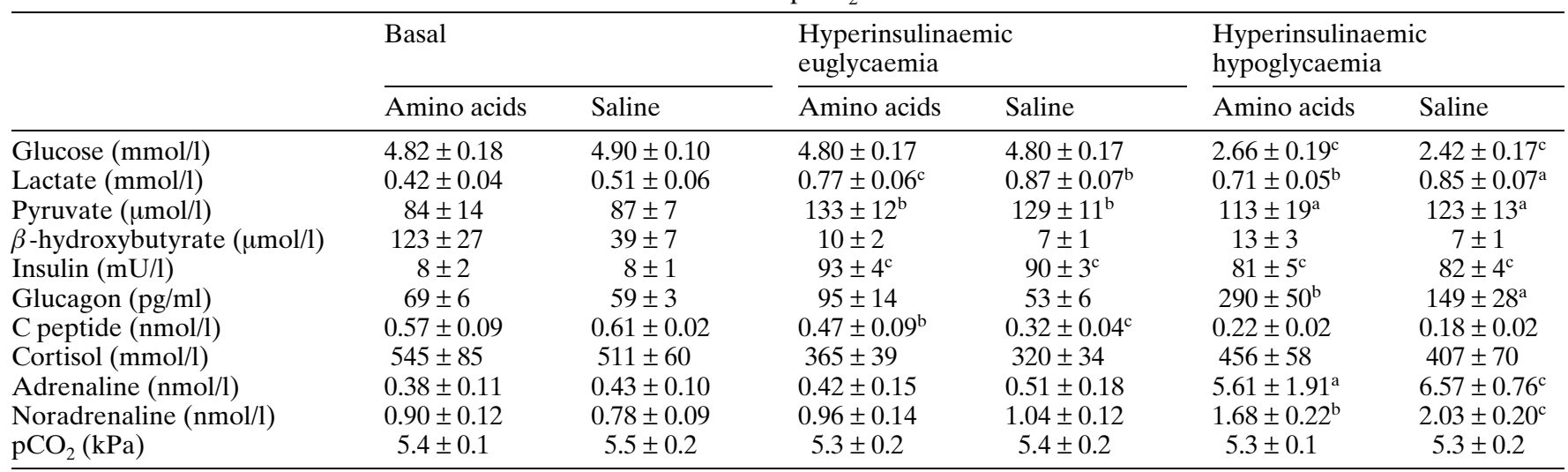

Data are expressed as means \pm SEM. Significance of differences from the corresponding basal value, ${ }^{\mathrm{a}} p<0.05,{ }^{\mathrm{b}} p<0.01$, ${ }^{\mathrm{c}} p<0.001$

Table 2. Arterial-jugular venous differences for substrates and oxygen

\begin{tabular}{|c|c|c|c|c|c|c|}
\hline & \multicolumn{2}{|l|}{ Basal } & \multicolumn{2}{|c|}{$\begin{array}{l}\text { Hyperinsulinaemic } \\
\text { euglycaemia }\end{array}$} & \multicolumn{2}{|c|}{$\begin{array}{l}\text { Hyperinsulinaemic } \\
\text { hypoglycaemia }\end{array}$} \\
\hline & Amino acids & Saline & Amino acids & Saline & Amino acids & Saline \\
\hline Lactate $(\mathrm{mmol} / \mathrm{l})$ & $-0.07 \pm 0.01$ & $-0.06 \pm 0.01$ & $-0.05 \pm 0.01$ & $-0.02 \pm 0.01$ & $-0.02 \pm 0.02^{\mathrm{b}}$ & $-0.01 \pm 0.01^{\mathrm{a}}$ \\
\hline Pyruvate $(\mu \mathrm{mol} / \mathrm{l})$ & $-7 \pm 2$ & $-9 \pm 3$ & $1 \pm 2$ & $3 \pm 1$ & $-1 \pm 2^{\mathrm{b}}$ & $2 \pm 3$ \\
\hline$\beta$-hydroxybutyrate $(\mu \mathrm{mol} / \mathrm{l})$ & $3 \pm 2$ & $2 \pm 1$ & $0 \pm 0$ & $0 \pm 0$ & $1 \pm 1$ & $0 \pm 0$ \\
\hline RQ & $0.93 \pm 0.03$ & $0.91 \pm 0.04$ & $0.90 \pm 0.06$ & $0.95 \pm 0.08$ & $0.94 \pm 0.13$ & $0.93 \pm 0.07$ \\
\hline
\end{tabular}

Data are expressed as means \pm SEM. Significance of differences from the corresponding basal value, ${ }^{\mathrm{a}} p<0.05,{ }^{\mathrm{b}} p<0.01$

ids were $4.8-7.8 \%$. Adrenaline and noradrenaline were determined by HPLC with electrochemical detection [18]. Concentrations of insulin [19] and cortisol [20] in serum and glucagon [21] in plasma were measured by radioimmunoassay. The blood content of oxygen and haemoglobin were analysed spectrophotometrically (OSM 3 Hemoximeter; Radiometer, Copenhagen, Denmark) (CV for oxygen content $1 \%$ ) and blood gases were measured on a blood gas analyser (ABL 4, Radiometer, Copenhagen, Denmark). Carbon dioxide content in plasma was measured using a Corning 965 Carbon Dioxide Analyzer (Corning Medical and Scientific Corning, Halstead, Essex, England).

Calculations. The oxygen content of blood was calculated from the oxygen saturation and the haemoglobin concentration, assuming that $1.34 \mathrm{ml} \mathrm{O}_{2}$ was bound per gram haemoglobin. Brain RQ was derived as the ratio of the arterial-jugular venous differences for oxygen and carbon dioxide. The contribution of glucose to the brain's oxidative metabolism was calculated assuming complete oxidation and consumption of 6 moles of oxygen per mole of glucose. Fractional extraction of glucose was estimated as the arterial-jugular venous glucose concentration difference divided by the arterial concentration.

Statistics. All values are expressed as means \pm SEM. Paired $t$ test was used to compare results for the two study days and one-way ANOVA for repeated measurements with testing after this was applied for comparison of data within the same study day (JMP, SAS Institute, Carey, N.C., USA).

\section{Results}

Basal state. Arterial concentrations of substrates and hormones in the basal state are presented in Table 1. The arterial-jugular venous (A-JV) differences for substrates, oxygen and carbon dioxide are shown in Table 2. Glucose uptake could account for $106 \pm 5 \%$ of the brain's oxidative metabolism as evaluated from the A-JV differences for glucose and oxygen (Fig. 2), consistent with the estimated cerebral RQ of $0.93 \pm 0.04$. There was a small release of both lactate and pyruvate from the brain. No net exchange of $\beta$-hydroxybutyrate could be detected. Arterial amino acid concentrations are indicated in Table 3. Statistically significant net cerebral exchange was not observed for any individual amino acid (Table 4). Arterial $\mathrm{pCO}_{2}$ was $5.5 \pm 0.1 \mathrm{kPa}$ in the basal state and remained unchanged throughout the study periods.

Euglycaemic clamp. During the euglycaemic clamp study insulin concentrations rose more than tenfold above basal (Table 1). The degree of hyperinsulinaemia was almost identical on the two study occasions. The insulin infusion was accompanied by a pronounced fall in the concentrations of the branched chain amino acids, glutamine, phenylalanine 


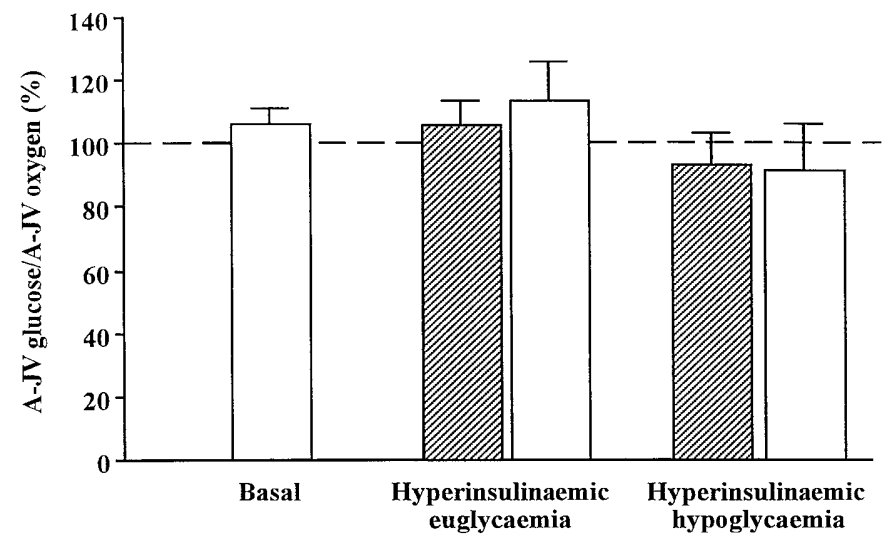

Fig. 2. Arterial-jugular vein (A-JV) concentration differences for glucose (expressed in oxygen equivalents) as per cent of A-JV differences of oxygen in the basal state, during hyperinsulinaemic euglycaemia and during hyperinsulinaemic hypoglycaemia. Data obtained in the basal state and during saline infusion are indicated by open bars, data from amino acid infusion are presented by hatched bars. Mean values \pm SEM are presented

and tyrosine during saline infusion (Table 3). With combined amino acid and insulin infusion considerable increments were seen for all amino acids except glutamine and tyrosine (not included in the infused solution) but uptake of amino acids to the brain could not be shown from the A-JV concentration differences (Table 4). The average glucose infusion rate during the $30-90 \mathrm{~min}$ period of the clamp study was lower during amino acid infusion $\left(6.62 \pm 0.61 \mathrm{mg} \cdot \mathrm{kg}^{-1} \cdot \mathrm{min}^{-1}\right)$ than during saline infusion $\left(8.10 \pm 0.95 \mathrm{mg} \cdot \mathrm{kg}^{-1} \cdot \mathrm{min}^{-1}, p<0.05\right)$.

The A-JV difference for glucose after 80-90 min remained similar to that in the basal state and did not differ during either amino acid or saline infusion (Table 2). Glucose uptake could be calculated to account for all of the oxidative metabolism both during amino acid and saline infusion (104-112\%, Fig. 2). Despite a 70-80\% rise in arterial lactate concentration, there was a net release of lactate from the brain
(Table 1, 2). Arterial pyruvate concentrations also rose by $50-60 \%$ but no statistically significant net cerebral exchange of pyruvate was observed. During the insulin clamp $\beta$-hydroxybutyrate concentrations decreased considerably and, as in the basal state, no net exchange across the brain was detected. Glucagon, cortisol, adrenaline and noradrenaline concentrations remained unchanged.

Hypoglycaemia. The blood glucose nadir during the hypoglycaemic period was on average $2.7 \pm 0.2$ and $2.4 \pm 0.2 \mathrm{mmol} / \mathrm{l}$ during amino acid and saline infusion, respectively (NS, Fig. 1). Lactate, pyruvate and $\beta$-hydroxybutyrate concentrations were unchanged during both saline and amino acid infusion compared with the euglycaemic period. Insulin concentrations decreased slightly $(9-12 \%, p<0.05-0.001)$ as compared with the preceding hyperinsulinaemic euglycaemic period (Table 1). Similar conditions were obtained during saline and amino acid infusion. Glucagon concentrations rose considerably compared with the basal state $(p<0.05-0.01)$ and more so during amino acid infusion $(p<0.05)$ (Table 1$)$. Adrenaline and noradrenaline concentrations increased tenand twofold, respectively, during hypoglycaemia $(p<0.01)$ and to a similar extent during amino acid and saline infusion.

The A-JV difference for glucose was essentially unchanged during hypoglycaemia as compared with the euglycaemic and basal periods (Table 2). The glucose difference was maintained during hypoglycaemia in part as a result of increased cerebral fractional extraction. It rose from approximately $10 \%$ in the basal state to $17-18 \%$ during hypoglycaemia $(p<0.01)$ (Fig.3). There was no statistically significant net exchange of lactate, pyruvate (Table 2) or amino acids (Table 4) across the brain. The A-JV oxygen difference during hypoglycaemia and saline infusion decreased by, on average, $13 \%$ compared with the basal value $(p<0.01)$ but remained unchanged during amino acid infusion (Table 2). During amino acid infusion glucose uptake could account for $92 \pm 10 \%$ of the oxi-

Table 3. Arterial concentrations of amino acids

\begin{tabular}{|c|c|c|c|c|c|c|}
\hline & \multicolumn{2}{|l|}{ Basal } & \multicolumn{2}{|c|}{$\begin{array}{l}\text { Hyperinsulinaemic } \\
\text { euglycaemia }\end{array}$} & \multicolumn{2}{|c|}{$\begin{array}{l}\text { Hyperinsulinaemic } \\
\text { hypoglycaemia }\end{array}$} \\
\hline & Amino acids & Saline & Amino acids & Saline & Amino acids & Saline \\
\hline Glutamine $(\mu \mathrm{mol} / \mathrm{l})$ & $631 \pm 34$ & $641 \pm 28$ & $609 \pm 30$ & $546 \pm 16^{\mathrm{a}}$ & $526 \pm 45$ & $516 \pm 17^{\mathrm{b}}$ \\
\hline Glycine $(\mu \mathrm{mol} / \mathrm{l})$ & $281 \pm 30$ & $305 \pm 33$ & $443 \pm 33^{b}$ & $274 \pm 27$ & $409 \pm 40^{\mathrm{a}}$ & $263 \pm 22$ \\
\hline Isoleucine $(\mu \mathrm{mol} / \mathrm{l})$ & $61 \pm 3$ & $63 \pm 7$ & $106 \pm 5^{c}$ & $31 \pm 2^{\mathrm{b}}$ & $100 \pm 3^{c}$ & $31 \pm 5^{b}$ \\
\hline Leucine $(\mu \mathrm{mol} / \mathrm{l})$ & $122 \pm 5$ & $124 \pm 10$ & $164 \pm 5^{c}$ & $69 \pm 3^{\mathrm{b}}$ & $154 \pm 5^{c}$ & $68 \pm 7^{b}$ \\
\hline Tyrosine $(\mu \mathrm{mol} / \mathrm{l})$ & $55 \pm 4$ & $58 \pm 5$ & $44 \pm 4$ & $37 \pm 3^{\mathrm{b}}$ & $41 \pm 5$ & $36 \pm 3^{b}$ \\
\hline Valine $(\mu \mathrm{mol} / \mathrm{l})$ & $238 \pm 8$ & $235 \pm 12$ & $339 \pm 12^{c}$ & $174 \pm 4^{\mathrm{b}}$ & $344 \pm 10^{c}$ & $173 \pm 8^{\mathrm{b}}$ \\
\hline
\end{tabular}

Data are expressed as means \pm SEM. Significance of differences from the corresponding basal value, ${ }^{\mathrm{a}} p<0.05,{ }^{\mathrm{b}} p<0.01$, ${ }^{\mathrm{c}} p<0.001$ 
Table 4. Arterial-jugular venous concentration differences for amino acids

\begin{tabular}{|c|c|c|c|c|c|c|}
\hline & \multicolumn{2}{|l|}{ Basal } & \multicolumn{2}{|c|}{$\begin{array}{l}\text { Hyperinsulinaemic } \\
\text { euglycaemia }\end{array}$} & \multicolumn{2}{|c|}{$\begin{array}{l}\text { Hyperinsulinaemic } \\
\text { hypoglycaemia }\end{array}$} \\
\hline & Amino acids & Saline & Amino acids & Saline & Amino acids & Saline \\
\hline Glutamine $(\mu \mathrm{mol} / \mathrm{l})$ & $15.6 \pm 13.6$ & $-3.3 \pm 20.2$ & $-5.5 \pm 7.0$ & $11.5 \pm 18.5$ & $4.2 \pm 12.6$ & $8.7 \pm 16.5$ \\
\hline Glycine $(\mu \mathrm{mol} / 1)$ & $2.7 \pm 2.5$ & $0.1 \pm 8.3$ & $6.2 \pm 7.4$ & $7.4 \pm 8.6$ & $10.8 \pm 10.5$ & $3.9 \pm 3.7$ \\
\hline Isoleucine $(\mu \mathrm{mol} / \mathrm{l})$ & $3.0 \pm 1.1$ & $-0.6 \pm 5.7$ & $6.5 \pm 4.2$ & $1.9 \pm 1.3$ & $5.2 \pm 2.2$ & $6.4 \pm 4.3$ \\
\hline Leucine $(\mu \mathrm{mol} / \mathrm{l})$ & $6.4 \pm 2.5$ & $0.6 \pm 10.2$ & $5.6 \pm 3.2$ & $5.6 \pm 3.0$ & $8.7 \pm 3.7$ & $11.9 \pm 7.1$ \\
\hline Tyrosine $(\mu \mathrm{mol} / \mathrm{l})$ & $0.9 \pm 0.5$ & $-0.7 \pm 3.2$ & $0 \pm 0.5$ & $0.9 \pm 1.4$ & $1.2 \pm 1.3$ & $3.1 \pm 2.6$ \\
\hline Valine $(\mu \mathrm{mol} / \mathrm{l})$ & $7.3 \pm 2.2$ & $1.2 \pm 12.1$ & $5.2 \pm 4.2$ & $10.0 \pm 7.6$ & $12.1 \pm 6.7$ & $16.2 \pm 9.3$ \\
\hline
\end{tabular}

Data are expressed as means \pm SEM

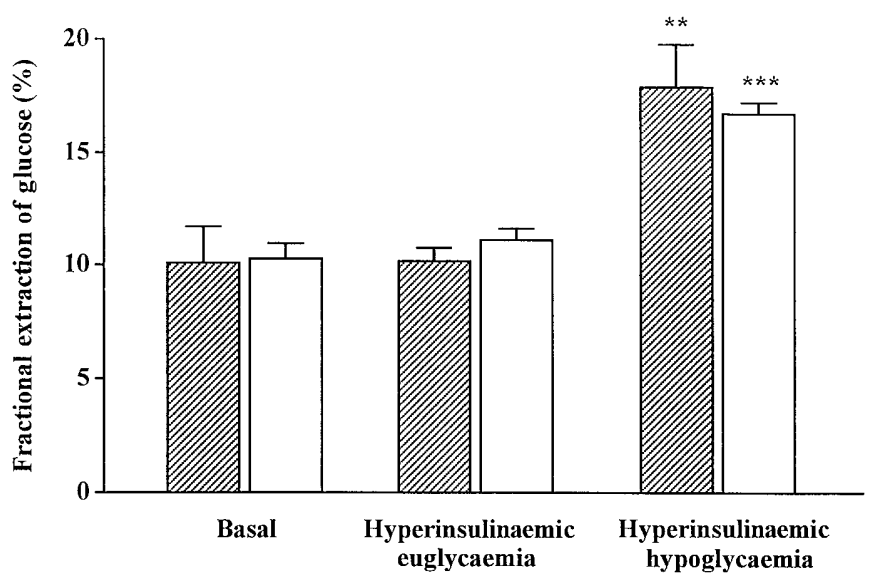

Fig.3. Fractional extraction of glucose in the basal state, during hyperinsulinaemic euglycaemia and during hyperinsulinaemic hypoglycaemia. Data obtained during saline infusion are indicated by open bars, data from amino acid infusion are presented by hatched bars. Means \pm SEM are given. Asterisks denote the differences from the corresponding value in the basal value, $* * p<0.01, * * * p<0.001$

dative metabolism of the brain; during the saline infusion the corresponding value was $90 \pm 15 \%$ (Fig. 2). In accordance with these data the estimated RQ of the brain was $0.94 \pm 0.13$ during amino acid infusion and $0.93 \pm 0.07$ during saline infusion.

\section{Discussion}

Our study confirms that glucose is the predominant substrate for the brain's oxidative metabolism in the overnight fasted, basal state during hyperinsulinaemic euglycaemia as well as during hyperinsulinaemic hypoglycaemia in healthy subjects. Circulating insulin appears to have no direct effect on glucose utilisation in the brain, despite recent observations in hypoglycaemic dogs and humans that the brain is sensitive to insulin $[22,23]$. In agreement with previous findings in dogs [24], brain glucose utilisation was of similar magnitude irrespective of the fall in circulating glucose from 4.8 to $2.4 \mathrm{mmol} / \mathrm{l}$ (Table 1). Maintenance of brain glucose uptake at the same level as during euglycaemia in the face of hypoglycaemia (Table 1) was achieved primarily by augmented fractional extraction of glucose (Fig.3). The increased fractional extraction was most likely secondary to the low blood glucose concentration and the unchanged fuel requirement of the brain. Accordingly, an increased clearance of glucose across the blood-brain barrier measured by the positron emission tomography technique has been reported during short-term hypoglycaemia in healthy subjects [25], but the mechanism for this is not clearly defined. Induction of the specific brain capillary endothelial glucose transporter (GLUT 1) has been shown in rats as an adaptation to chronic hypoglycaemia [26, 27]. Our study was designed, however, to determine the effect of acute rather than chronic hypoglycaemia and it is not clear whether an adaptation of glucose transport occurs on a short-term basis. It may require exposure to a more prolonged period of hypoglycaemia than used in this study.

An adaptive increase in cerebral blood flow of 5-20\% may occur during hypoglycaemia [28, 29], thereby increasing total blood glucose availability to the brain. Cerebral blood flow was not measured in our study. That the A-JV oxygen difference decreased by $12 \%$ during hypoglycaemia provides indirect evidence that an increase in blood flow could have occurred (Table 2). It should, however, be recognised that an increase in cerebral blood flow during hypoglycaemia does not influence our study's main conclusion inasmuch as the relation between the A-V arterio-venous differences for oxygen and substrates is flow independent. Combined measurements of oxygen and substrate $\mathrm{A}-\mathrm{V}$ differences thus provide a valid indication of relative contribution of the different oxidisable fuels, irrespective of blood flow, but the evaluation requires the assumption that the substrate taken up is oxidised rather than stored. In addition, it is recognised that regional differences in the brain's substrate utilisation cannot be evaluated. 
The simultaneous measurement of A-JV differences for glucose and oxygen allowed us to estimate the contribution made by glucose to total brain oxidative metabolism. These estimations indicate that in the basal state and during hyperinsulinaemic euglycaemia the glucose contribution was very close to $100 \%$ (96-112\%, Fig. 2$)$. The corresponding data for hypoglycaemia - with and without hyperaminoacidaemia - were, however, 90-92\%. Although it is recognised that the number of subjects participating in the study is small $(n=6)$ and compounded methodological errors preclude exact determination of the contribution made by glucose to the total substrate requirement, the data raise the possibility that substrates other than glucose may have been used by the brain during hypoglycaemia. Yet, direct measurements of lactate and pyruvate did not indicate cerebral utilisation of these substrates although the arterial concentrations of both substrates were increased by $50-80 \%$ during hypoglycaemia (Table 2). The current study, therefore, provides no mechanistic explanation of why augmented availability of lactate (fourfold to fivefold above basal) improves symptomatic awareness and cerebral dysfunction during hypoglycaemia as reported previously $[3,30]$. Increased amino acid availability during hypoglycaemia induced by exogenous amino acid infusions in our study did not result in a noticeable brain uptake of amino acids. A previous study [31] shown that a tenfold increase of $\beta$-hydroxybutyrate prevents counter-regulatory hormonal responses during hypoglycaemia, suggesting a rapid adaptation of the brain's utilisation of non-glucose substrates. In our study circulating $\beta$-hydroxybutyrate concentrations were low, presumably due to the high insulin concentrations. Although glucose accounts for $90-92 \%$ of the brain's oxidative metabolism during hypoglycaemia none of the substrates measured in our study were considered to account for the remaining $8-10 \%$ of fuel utilisation of brain. Thus, the possibility may be considered that locally derived substrates, as suggested previously [32], or glycerol accounted for the small difference between glucose uptake and total oxidative metabolism of brain. In this context it is noteworthy that locally derived substrates are reported to be used by the rat brain during severe hypoglycaemia [32]. In addition, glycogen in astrocytes has been suggested as a source of glucose for the brain under extreme conditions such as open heart surgery [33].

Since our results indicate that neither amino acids nor lactate or pyruvate are used by the brain even during hypoglycaemia, it becomes important to consider the quantification of the minimum detectable substrate arterio-venous differences. Precise calculations cannot readily be made but using the methodological errors reported in the Methods section and assuming a worst case scenario (overestimation of ar- terial and underestimation of jugular venous concentrations) the possible undetected contribution made by, e.g leucine, can be estimated to account for approximately $2 \%$ of the brains oxidative metabolism. The corresponding value for alanine is $5 \%$ and for lactate $3 \%$. Consequently, a small contribution $(<8-10 \%)$ by amino acids or lactate to the brain's oxidative metabolism cannot be excluded but the above considerations make it unlikely that a major contribution is made by substrates other than glucose.

As could be expected, adrenaline, noradrenaline and glucagon concentrations all rose during hypoglycaemia (Table 1). In the case of adrenaline and noradrenaline, the rises were similar during saline and amino acid infusion. Glucagon increase was, however, $95 \%$ greater during amino acid infusion, confirming that the glucagon response to insulin-induced hypoglycaemia is enhanced by treatment with amino acid [11]. Amino acid infusion reduced the amount of glucose needed to maintain euglycaemia, as reported previously [34], due to either decreased glucose disposal or increased glucose production. Increased amino acid infusion has been reported to decrease forearm glucose uptake [35], suggesting a decreased glucose disposal. The mechanism of this amino acid induced glucose sparing is unclear, although increased amino acid utilisation is a possibility. An increased glucose production related to increased glucagon concentrations is, however, unlikely since in the presence of high circulating insulin, glucagon may not stimulate glucose production.

In conclusion, the current study shows that glucose is the predominant substrate for the brain and that the brain uses nearly the same amount of glucose during hypoglycaemia as in the euglycaemic state. This is achieved by an increase in brain fractional extraction of glucose. Increased availability of endogenously produced lactate and pyruvate or exogenously infused amino acids did not result in uptake of these substrates even when the circulating glucose concentrations were very low. The possibility that the brain uses small amounts of locally derived substrates or glycerol remains to be examined.

Acknowledgements. This work was supported by National Institutes of Health (grant DK 41973) and a grant from the Karolinska Institute.

\section{References}

1. DCCT Group (1993) The effect of intensive treatment of diabetes on the development and progression of long-term complications in insulin-dependent diabetes mellitus. New Engl J Med 329: 977-983

2. Amiel S (1994) Hypoglycaemia without warning: a dangerous but reversible phenomenon. The Endocrinologist 4: 433-441 
3. Maran A, Cranston I, Lomas J, MacDonald I, Amiel SA (1994) Protection by lactate of cerebral function during hypoglycaemia. Lancet 343: 16-20

4. Siesjö B (1978) Utilization of substances by brain tissue. Brain energy metabolism. Wiley, New York, pp 101-130

5. Amiel SA (1995) Organ fuel selection: brain. Proceedings of Nutrition Society 54: 151-155

6. Ahlborg G, Wahren J (1972) Brain substrate utilization during prolonged exercise. Scand J Clin Lab Invest 29: 397-402

7. Avogaro A, Nosadini R, Doria A et al. (1990) Substrate availability other than glucose in the brain during euglycemia and insulin-induced hypoglycemia in dogs. Metabolism 39: 46-50

8. Redies C, Hoffer J, Beil C et al. (1989) Generalized decrease in brain glucose metabolism during fasting in humans studied by PET. Am J Physiol 256:E805-E810

9. Owen OE, Morgan AP, Kemp HG, Sullivan JM, Herrera MG, Cahill GF Jr (1967) Brain metabolism during fasting. J Clin Invest 46: 1589-1595

10. Alvestrand A, DeFronzo R, Smith D, Wahren J (1988) Influence of hyperinsulinemia on intracellular amino acid levels and amino acid exchanges across splanchnic and leg tissues in uraemia. Clin Sci 74: 155-163

11. Nair KS (1990) Effects of plasma amino acid replacement on glucagon and substrate responses to insulin-induced hypoglycemia in humans. Diabetes 39: 376-382

12. Nadeau D, Nair K (1991) Amino acid enhances glucose recovery from insulin-induced hypoglycemia in type I diabetes. Clin Res 39: 385A

13. Felig P, Wahren J, Ahlborg G (1973) Uptake of individual amino acids by the human brain. Proceedings of the Society for Experimental Biology \& Medicine 142: 230-231

14. Grill V, Björkman O, Gutniak M, Lindqvist M (1992) Brain uptake and release of amino acids in nondiabetic and insulin-dependent diabetic subjects: important role of glutamine release for nitrogen balance. Metabolism 41: 28-32

15. Banauch D, Brümmer W, Ebeling W et al. (1975) Eine Glucose-Dehydrogenase für die Glucose-Bestimmung in Körperflüssigkeiten. Z Klin Chem u Klin Biochem 13: 101-107

16. Bergmeyer HU (1974) Methods of enzymatic analysis. Academic Press/Verlag Chemie, New York

17. Jones B, Gilligan J (1983) Amino acid analysis by $O$-pthaldehyde precolumn derivatization and reversed phase HPLC. Am Biotechnol Lab 12: 45-51

18. Hjemdahl P, Daleskog H, Kahan T (1979) Determination of plasma catecholamines by high performance liquid chromatography with electrochemical detection: comparison with a radioenzymatic method. Life Sci 25: 131-138

19. Livessy J, Hodgkinson S, Roud H, Donald R (1980) Effect of time, temperature and freezing on the stability of immunoreactive $\mathrm{LH}, \mathrm{FSH}, \mathrm{TSH}$, growth hormone, prolactin and insulin in plasma. Clin Biochem 13: 151-155

20. Dash R, England B, Midgley A, Niswender G (1975) A specific, non-chromatographic radioimmunoassay for human plasma cortisol. Steroids 26: 647-661
21. Harris W, Faloona G, Unger R (1979) Glucagon. In: Jaffe $\mathrm{B}$, Behrman $\mathrm{H}$ (eds) Methods of hormone radioimmunoassay. Academic press, New York, pp 643-655

22. Lingenfelser T, Overkamp D, Renn W et al. (1996) insulinassociated modulation of neuroendocrine conterregulation, hypoglycemia preception, and cerebral function in insulin-dependent diabetes mellitus: evidence for an intrinsic effect of insulin on the central nervous system. J Clin Endocrinol Metab 81: 1197-1205

23. Davis S, Colburn C, Dobbins R et al. (1995) Evidence that the brain of the conscious dog is insulin sensitive. J Clin Invest 95: 593-602

24. Sieber F, Koehler R, Derrer S, Saudek C, Traystman R (1990) Hypoglycemia and cerebral autoregulation in anesthetized dogs. Am J Physiol 258:H1714-H1721

25. Blomqvist G, Gjedde A, Gutniak M et al. (1991) Facilitated transport of glucose from blood brain in man and the effect of moderate hypoglycemia on cerebral glucose utilization. Eur J Nucl Med 18: 834-837

26. Kumagai A, Kang Y-S, Boado R, Pardridge W (1995) Upregulation of blood-brain barrier GLUT1 glucose transporter protein and mRNA in experimental chronic hypoglycemia. Diabetes 44: 1399-1404

27. Koranyi L, Bourey R, James D, Mueckler M, Fiedorek FJ, Permutt MA (1991) Glucose transporter gene expression in rat brain: pretranslational changes associated with chronic insulin-induced hypoglycemia, fasting and diabetes. Mol Cell Neurosci 2: 244-252

28. Tallroth G, Ryding E, Agardh C (1992) Regional cerebral blood flow in normal man during insulin-induced hypoglycemia and in the recovery period following glucose infusion. Metabolism 41: 717-721

29. Jarjour TI, Ryan CM, Becker DJ (1995) Regional cerebral blood flow during hypoglycemia in children with IDDM. Diabetologia 38: 1090-1095

30. King P, Kong MF, Parkin H, MacDonald I, Barber C, Tattersall R (1998) Intravenous lactate prevents cerebral dysfunction during hypoglycemia in insulin-dependent diabetes mellitus. Clin Sci 94: 157-163

31. Amiel S, Archibald H, Chusney G, Gale E (1991) Ketone lowers hormone responses to hypoglycemia - evidence for acute cerebral utilization of a non-glucose fuel. Clin Sci 81: 189-194

32. Agardh C, Chapman AG, Nilsson B, Siesjo BK (1981) Endogenous substrate utilized by rat brain in severe insulininduced hypoglycemia. J Neurochem 36: 490-500

33. Eyre JA, Stuart AG, Forsyth RJ, Heaviside D, Bartlett K (1991) Glucose export from the brain in man: evidence for a role for astrocytic glycogen as a reservoir of glucose for neural metabolism. Brain Research 635: 349-352

34. Tessari P, Inchiostro S, Biolo G et al. (1985) Hyperaminoacidaemia reduces insulin-mediated glucose disposal in healthy man. Diabetologia 28: 870-872

35. Schwenk WF, Haymond MW (1987) Decreased uptake of glucose by human forearm during infusion of leucine, isoleucine, or threonine. Diabetes 36: 199-204 